\title{
The Research on Second Language Acquisition Model Based on the Dynamic Systems Theory*
}

\author{
Ying Tian \\ Northeast Electric Power University \\ Jilin, China
}

\begin{abstract}
Many factors in the second language acquisition (SLA) and the interconnectedness among these factors formed a complex dynamic system, which determines the speed and level of SLA. Based on the dynamic systems theory and the existed model of SLA, the researcher is making a great effort to build a new dynamic model of SLA under the current Chinese learning environment. This model consists of three parts: the environmental factor, the learners' factor, and the language factor. The environmental factor refers to the social environment, learning environment and linguistic environment. The learner's factor is involved in the individual cognition difference, affection difference and the difference of learning strategies. The language factor emphasizes the structural features of language. As we all know that Chinese learners acquire the second language after the mother tongue, so language transfer is inevitable. We should consider how to avoid the effects of language negative transfer. This essay attempts to analyze the interactions among the three factors and their effects on SLA as well as their enlightening on foreign language teaching.
\end{abstract}

keywords - environment; learners; language; learning model; dynamic systems theory

\section{INTRODUCTION}

Since the 1980s, the researchers in linguistic field, psychological field and educational field created lots of second language acquisition model with the systematic features in order to know about the features and rules of the second language development. Because there are differences on its origin as well as its purpose for the second language acquisition model, they showed different emphasis on content. Such as, certain model focuses on the social educational factors. (Gardner, 1985), and certain model focuses on the learning process (Gass\&Selinker, 2008) or emphasizes the cognition process. But all these models had a common characteristic which they didn't take the interconnectedness of factors into consideration. Being based on the existed SLA model and dynamic systems theory, with environment, learners and language as its core factors, the researcher attempts to build a new acquisition model. This research is a supplement to the related fields, and hopes to enlighten the foreign language teaching.

*Sponsored by Education Department of Jilin Province (Gran No.2016057) and Education Department of Jilin Province (Grant No.2016056)

\section{THE SLA MODEL UNDER THE DYNAMIC SYSTEMS THEORY}

\section{A. The International Theory Research}

The international SLA theory mainly includes Krashen's monitor theory (1982), Gardner's social educational model (1985), Ellis's framework of SLA (1994), and Spolsky's general model. For Krashen's SLA monitor model, it emphasizes the different effects on the language ability development between conscious learning and unconscious acquisition. It also points out different functions of input (environment), affection filter (learners) and monitor (psychological mechanism) in the SLA. For Gardner's social educational model, it summarized that social cultural perception and learners' cognition have great influence on the result of SLA. In Ellis's framework of SLA, social factors, (external factors), language mechanism (internal factors) and individual learners intermingled with each other by different ways, which can have great influence on the results of SLA. Each model focused on certain factor of second language acquisition, and it didn't take the interconnectedness of different factors into consideration. It is inevitable that all the existed models can't cover the dynamic connection among all the factors in the second language acquisition.

\section{B. The Basic Features of Dynamic Systems Theory}

The dynamic systems theory is featured by the complete interconnectedness, which means that all the variables involved in the dynamic systems theory are connected with each other. In other words, the change of one variable will affect the changes of other variables. (de Bot, 2008) The system is very sensitive to the initial condition, and the little original differences will have great effect on the later development. That is called butterfly effect. The system is sometimes in the condition of chaos, which stems from the connectedness of variables as well as the little original differences. But there is certain rule under the condition of chaos. The language development is determined by the interaction between internal and external resources. In order to achieve success in learning, on the one hand, some important learning resources such as, memory, motivation, input etc must meet the minimum requirements; on the other hand, these internal and external resources are compensated with each other, eg, the hard work will compensate the shortage of learning time. The change of one factor will lead 
to the changes of interactions with the other factors, and this corresponds with interactional model (Carroll) as well as disjunctive model (Skehan). Carroll's interactional model emphasized the difference of one variable affected the performance of other variables. For example, the increase of learning time and improvement of teaching quality can make up for the deficiency of learner's low aptitude. Skehan's disjunctive model focused on that the learning outcome can be achieved by different ways. In other words, certain outcome can be achieved by different routes. For example: one learner can achieve success with the auditory intelligence, while the other learner can achieve high aims with good memory. Both of them achieved the same outcome, but the methods they adopted are different.

\section{The Three Subsystems under the Dynamic Systems Theory}

1) Environment Factor: The environment factor includes social environment, linguistic environment and learning environment. Stern (1983) thinks that social environment includes social linguistics, social culture and social economic factors. In Gardner's model, the social environment mainly refers to the cultural conception, besides, geographical location and language policy will also affect the learning outcome as the external environment factors. Linguistic environment mainly refers to the monolingual or bilingual social environment, which has influence on the learner's attitude, motivation and opportunities of language practice. The learning environment mainly involves the formal environment (classroom environment) and informal environment (natural environment). The learning environment has great effect on the input of language, language interaction and output of language.

2) Learners' Factor: The factor of learners includes three categories: differences of individual cognition, affection difference and learning strategy. Among them, the individual cognition difference involves intelligence, language learning aptitude and memory, etc. The individual affection difference includes learning motivation and attitude, personalities, the feeling of anxiety and learning styles. The learning styles can also be divided into metacognitive strategy, cognitive strategy and affection strategy. The factor of individual cognition difference is closely related with the achievement of second language acquisition. Based on the findings of Gardner and Skehan, it is believed that learning motivation and language aptitude are the predictable factors for the results of second language acquisition. Ellis firmly believed that the interpretation of second language acquisition was not complete without considering the factor of individual cognition difference. The factor of learners has great effect on the input, interaction and output of second language acquisition. (Robinson, 2002)

3) Language Factor: Although the first language acquisition is similar to the second language acquisition, there are still some of the differences. First, the second language learners learn language with the model of mother tongue, and the basis has great influence on cross language, which was reflected on the process of words replacement, overgeneralization and excessive error correction etc.(Odlin, 1989) Second, although the mother tongue and the second language acquisition are the process of social cognition, the second language learners are more mature in the process of language cognition, and the language acquisition environment is quite different from that of children. It is more complex for the second language learners to understand the second language than the first language from the aspects of cognitive linguistics, psychological linguistics and social linguistics, because the factors intermingled with each other dynamically. The most intelligence second language learners can't reach the level that children can acquire.

4) The Dynamic Internal Features of Subsystems and Its Effects on SLA

The factors of subsystems interacted with each other. Take the language learners as an example, the learners' motivation influence the learning strategies; language aptitude and intelligence are independent, but they also intersect with each other(Sasaki, 1993); besides, the intersection of language aptitude and learners' sex also have effect on the SLA (戴运才, 2006). So Oxford once pointed out, language aptitude, learning methods and learning strategies are closely related with each other. Take another factor as an example, in the subsystem of environment, the monolingual or bilingual environment not only affects the input and output of language in the process of SLA, it also influences the learners' attitude. From the aspect of subsystems effects on SLA, the three subsystems can have effects on SLA directly. Take the linguistic environment factor as an example, it influences the quantity and quality of input, as well as the opportunity of output. If the learner is in the open social environment, and he can study the second language in earlier age, so the longer he studies the second language, the more opportunities he will have to the language output. For another example, if the learner studies the second language in the bilingual social environment, he can reach more forms of the target language. For the language learners, the individuals are different in cognition, intelligence, language aptitude and memory, which not only determine the learner's process and storage of SLA, but also has significant effects on the interlanguage fusion. For the linguistic factor, the non-marked mother tongue form is more easily to transfer, while the high marked form is less likely to transfer. (Eckman, 1977) The distance of language also has effect on language transfer. The closer distance between the target language and mother tongue is, the easier to acquire the second language for the learners.

5) The Dynamic External Features of Subsystems and Its Effects on SLA

The environment factor, learners' factor and linguistic factor not only act with each other internally, but also the intersection influences the interlanguage development. First, the environment and learners interact with each other and influence the result of SLA. For example, in the classroom 
environment, the learners' belief, aim, value, class organization and interpersonal relationship among students will have influence on the students' knowledge assimilation in the class. In addition, the learners' memory capacity interacted with teaching methods of the environment factor, which has certain function on the SLA. The language learners with good analysis ability and large memory storage will benefit a lot from the teaching method which emphasizes the input instead of the out of language. Second, the interaction of environment factor and the linguistic factor influences the quality of language processing. For example, in the language environment which put much emphasis on the language forms, many concerns will be given to the differences between the different forms of mother tongue and the target language. Therefore, this will avoid the language negative transfer effectively.

\section{THE ENLIGHTENMENT ON FOREIGN LANGUAGE TEACHING}

Just as discussed above, the dynamic systems of SLA includes three subsystems: language, learners, and environment. First, for the environment factor, learning environment in China is extremely important, which determines the learning outcome. So we should create good learning atmosphere by fully using different environment. As we all know, China is a monolingual country which is quite different from Canada or Singapore, where learners can reach the target language through different media or forms. In order to make up the deficiencies of monolingual environment, one of the efficient ways is to increase the input of second language after class, Carrying on all kinds of language activities and providing multimoding input of language. Second, for the learners' factor, it is the internal factor which influences the outcome of learning. It is particularly important to develop learners' subjective initiative. We can achieve this from the following three aspects: inspire the learners' motivation and cultivate learners' positive attitude; train learning strategies based on different learning tasks; teach learners in accordance with their aptitude. Third, for the language factor, because there are different forms for different languages, and the Chinese language learners acquire the second language after the mother tongue. It is inevitable to the language transfer for the mother tongue in the SLA. The key is how to deal with the language transfer reasonably. On the one hand, analyzing and comparing the differences between mother tongue and target language, so as to attract the learners' attention. The learners' psychological awareness should be increased on the related language, so as to avoid the negative transfer of target language. On the other hand, try to avoid mechanical comparison between two languages excessively. Social linguistic factors, psychological linguistic factors and cognitive factors can result in the language transfer, so only by the interactions of the various factors can avoid the negative transfer of language.

\section{CONCLUSION}

The essay analyzed the subsystems which influence the SLA in detail: What are the functions of environment, learners and language on the SLA, and the elaboration of the interplay of the three subsystems. The author is trying to create a new SLA model under Chinese learning environment. On the one hand, we can thoroughly explain the internal connection among the three subsystems which affect the SLA; on the other hand, we can adjust the teaching methods effectively and optimize all kinds of learning resources to improve the learning outcome. However, the new model is based on the research of SLA, and the factors connection in dynamic system theory is very complex. So we still need to explore its enlightenment on foreign language in the empirical research.

\section{REFERENCES}

[1] de Bot, K. Second Language development as a dynamic process [J]. The Modern Language Journal, 2008,92:166-178.

[2] Eckman, F. Markedness and the contrastive analysis hypothesis [J] Language Learning,1977, 27: 315-330.

[3] Ellis, R. The Study of Second Language Acquisition ( $1^{\text {st }}$ edition) [M] Oxford: Oxford University Press, 1994.

[4] Gardner R. Social Psychology and Second Language Learning: The role of Attitude and Motivation [M]. London: Edward Arnold, 1985.

[5] Krashen, S. Principles and Practice in Second Language Acquisition [M]. Oxford: Pergamon Press, 1982.

[6] Laser-Freeman, D. Chaos/complexity science and Second Language Acquisition [J]. Applied Linguistics,1997,18: 141-165.

[7] Laser-Freeman, D\&L. Cameron. Complex Systems and Applied Linguistics [M]. Oxford: Oxford University Press, 2008.

[8] Odlin, T. Language Transfer [M]. Cambridge : Cambridge University Press, 1989.

[9] Robinson, P. Consciousness, Rules, and Instructed Second Language Acquisition [M]. New York: Peter Long, 1996. 